\title{
Single-center Experience in the Treatment of Extremely Medial Clavicle Fractures with Vertical Fixation of Double-plate
}

He Liu

Jilin University Second Hospital https://orcid.org/0000-0001-7178-0276

Ziyan Zhang

Jilin University Second Hospital

Baoming Yuan

Jilin University Second Hospital

Guangkai Ren

Jilin University Second Hospital

Junlong Yu

Rushan people hospital

Chuangang Peng

Jilin University Second Hospital

Dankai Wu ( $\nabla$ wudankai@163.com )

Technical advance

Keywords: Extremely Medial clavicle fracture; Vertical fixation; Double-plate

Posted Date: October 2nd, 2019

DOI: https://doi.org/10.21203/rs.2.15445/v1

License: (c) (1) This work is licensed under a Creative Commons Attribution 4.0 International License.

Read Full License 


\section{Abstract}

Background: Patients suffering from medial clavicle fractures combined with displacement need surgical intervention. This research reports the effect of double-plate fixation as an innovative procedure in the treatment of extremely medial clavicle fractures.

Methods: Nine patients complaint of extremely medial clavicle fracture were enrolled in this research from Mar 2017 to March 2018. Patients were treated with an open reduction and internal fixation using the double-plate technique. Postoperative X-ray was taken regularly to observe the fracture healing at each visit, and the related complications were also recorded. The rating score systems of Constant Murley score of treated shoulder and contralateral shoulder, Rowe score as well as American Shoulder and Elbow Surgeons (ASES) were questionnaire to evaluate postoperative shoulder joint function.

Results: All patients achieved postoperative fracture healing with no complications. Only one patient complained of slight restriction, two patients complained of pain during overhead work, and another patient occurred plate breakage. Meanwhile, the Constant Murley scores of treated and contralateral shoulder were 94.1 and 98.5 points, respectively, indicating the similar shoulder function. Furthermore, the Rowe and ASES scores of the involved shoulder were 96.7 and 96.3 points at average, respectively.

Conclusions: It is the first time to introduce the surgical technique of vertical double-plate fixation for stable fixation of extremely medial clavicle fractures, which could provide the surgeons an alternative method for this type of fracture.

\section{Background}

The extremely medial clavicle fracture refers to the fracture locating at the $1 / 5$ position of the medial clavicle, with or without sternoclavicular joint dislocation, accounting for $3 \%$ to $6 \%$ of the clavicular fracture [1]. General conservative treatment can achieve considerable curative effect, which is generally feasible for type I A fractures in the Edinburgh classification. But patients with obvious displacement, sternoclavicular joint dislocation or vascular and nerve injury generally need surgical treatment [2].

Kirschner-wire and tension band is conducive to fracture healing and reliable fixation, which can help the early functional exercise of the shoulder and the recovery of joint function, etc. However, the tension strength of the Kirschner-wire and tension band is instability, and it is easy to cause re-fracture, dislocation, loosening, withdrawal, migration as well as vascular injury and nerve compression [3-4]. T shaped locking plate fixation can also be used for the treatment of clavicle fractures, which is fixed by a single cortex as far as possible to avoid damage to adjacent tissues. While, the fixation is poor and early postoperative functional exercise may result in stress concentration causing the plate loosen or refracture [5]. The clavicular hook plate is another routine procedure, but characterized with poor resistance to twisting and rotation, which is easy to break through the sternum. Meanwhile, it is difficult to remove the hook plate, which may damage the sternoclavicular joint [6]. Reconstruction plate is another alternative implant, which should be careful to avoid damage to the subclavian arteries, veins and 
brachial plexus, penetrating the mediastinum and pleura, etc., causing serious complications. Meanwhile, the plate is thin, and the clavicle is subjected to large shear force and stress shielding, appropriate external fixation may be needed after operation to avoid fixation failure and affect fracture healing [7].

Double-plate fixation is a common technique in the treatment of complex fractures of the distal radius or ulna $[8,9]$. Successful treatment of clavicle distal Neer II fractures has been confirmed with double fracture-fixation techniques, which can effectively improve the fixation stability [10]. Furthermore, the biomechanical testing demonstrated that double plate technique was mechanically superior to the single plate technique in lateral clavicle fractures fixation [11]. In this research, we at the first time to investigate the feasibility for the treatment of medial clavicle fractures using the double-plate fixation technique.

\section{Methods}

The study was approved by the ethics committee of The Second hospital of Jilin University. 9 patients with medial clavicle fracture were recruited in this research, including 7 female patients and 2 male patients whose age range from 35 to 72 , medium 62. These patients were treated with open reduction and internal fixation using the double-plate technique (Fig. 1 A and B) from Mar 2017 to March 2018. X ray examination and 3D reconstruction (Fig. $1 \mathrm{C}$ and $\mathrm{D}$ ) were obtained from each patient. According to the Edinburgh Classification, among the 9 patients four types of fracture were included: type AI (2 cases), type A II type (2 cases), type B I (4 cases), and type B II (1 case). The fracture classification of involved patients was listed in Table 1.

\section{Surgical Technique}

After brachial plexus anesthesia, the patient was fixed at a beach chair position, and the injured shoulder was padded with clavicle fracture centered. The transverse incision above the clavicle was applied to expose the sternoclavicular joint. Remove the surrounding soft tissue and peel the inserted periosteum in the fracture end (Fig. 2A). Then, absorbable non-invasive suture for bundling or Kirschner-wire for temporary fixation was used to make sure the clavicular reduction and avoid shortening deformity, which was also checked by X-ray examination (Fig. 2B). Subsequently, a 2.4/2.7 mm locking compression plate (BD-SIT, Beijing, China) was bent according to the anatomic position of the clavicle, and positioned on the cranial surface of the clavicle. And then, the plate was fixed with three cortical screws, which were inserted into the distal clavicle fragment. The second $2.4 / 2.7 \mathrm{~mm}$ locking compression plate was placed vertically to the first plate on the anterior surface of the clavicle (Fig. 2C). After the final X-ray examination, the incision was sutured layer by layer (Fig. 2D) and pressure bandages were added on the wound. Additionally, plate selection for medial clavicle fracture fixation using double-plate system, and four kinds of plate combinations are listed (Fig. 3).

\section{Postoperative Treatment}


24 hours after operation, functional activities such as forearm rotation, flexion and extension of the elbow joint were performed. One week after the operation, the upper limbs were able to perform a small range of flexion, extension and shrug. Functional exercise could begin at 2 weeks and no weight-bearing activity was recommended at 6 weeks postoperatively. We performed regular radiographic follow-up at 3, 6, 9 and 12 months after surgery. Postoperative X-ray was taken regularly to observe the fracture healing at each visit, and the related complications were also recorded. Meanwhile, the rating score systems of Constant Murley score [12], Rowe score as well as American Shoulder and Elbow Surgeons (ASES) were questionnaire at the end of follow-up to evaluate postoperative shoulder joint function $[13,14]$.

\section{Results}

All the nine patients were followed up for at least 6 months with an average of 10.2 months (from 6 to 18 months). X-ray showed all patients achieved postoperative fracture healing at an average of 3.6 months (from 3 to 6 months) (Fig. 4). After bone healing, no patient was reported with pain during rest. There was mild pain in two patient's affected side (22.2\%) during overhead work (VAS 0-10, average score is 0.8 ), and the satisfaction degree of all patients is at average of 9.3 points. In one patient $(11.1 \%)$, his shoulder internal rotation, abduction and adduction were basically the same as the healthy side, and only the active external rotation was slightly restricted. Plate breakage was found in one patient at the 3 months follow-up with no evidence of fracture displacement, and his plates were removed 12 months post operation. There were no other complications, such as fractures around the plate, screws loosing, joint instability and displacement. At the last follow-up, there were no complications, such as failure of internal fixation, nonunion, fractures around the plate or traumatic arthritis, were recorded. (See table 1)

Implants of two patients (22.2\%) were removed at 12 and 18 months after surgery, respectively. All patients went back to work except for 3 patients who already retired. Meanwhile, the Constant Murley scores of treated and contralateral shoulder were 94.1 and 98.5 points, respectively, indicating the similar shoulder function. Furthermore, the Rowe and ASES scores of the involved shoulder were 96.7 and 96.3 points at average, respectively. These rating score systems demonstrated good recovery of injured medial clavicle fractures collectively (Table 2).

\section{Discussion}

Medial clavicle fractures often involve the rupture of sternoclavicular surface and/or ligament, which is an unstable fracture [15]. Non-surgical treatment is difficult to obtain anatomical reduction with delayed healing and high nonunion rate, although without anesthetic risk, osteomyelitis, vascular nerve injury and other surgical complications [16]. Therefore, surgical treatment should be performed as soon as possible if the general condition of the patient allowed for surgery. The purposes of operation aim to dissect and reduce the fracture, prevent shortening deformity, avoid deformity healing, and strengthen and fix the fracture firmly. It does not affect the activity of the sternoclavicular joint and the functional exercise of the early shoulder joint. As described previously, the traditional fixation methods have a high failure rate and 
many complications in the treatment of the medial clavicle fractures. And, what kind of internal fixation method is perfect for medial clavicle fixation is still a major problem.

The advantages of double-plate fixation technique in the successful treatment of distal clavicle Neer II B fractures have been confirmed, which can effectively improve the fixation effect $[10,11]$. In this research, we chose two $2.4 / 2.7 \mathrm{~mm}$ locking compression plates to vertically fix medial clavicle fracture with 4-6 slender screw locking plates. This double-plate fixation system possesses several advantages. I. Doubleplate fixation could provide sufficient fixation, and small fracture fragments have better gripe. This vertical arranged plate and screws system could ensure the stable fixation of the medial clavicle end; II. Double row screws pressurized fixation in different directions could make sure more secure fixation. This theory has been verified by the biomechanical study that the opposing force of the screw in the front of the medial clavicle is the lateral shear force load, which could reduce the axial strength and stress shielding effect [17]; III. seven patients were over 50 years old is this study, and no patients turnout bone nonunion and plate fixation failure, indicating a reliable fixation even for patients with osteoporosis; IV. The sternoclavicular joint is not involved in the screw fixation, and the activity of the sternoclavicular joint is not affected, so the shoulder joint function exercise could be started in the early postoperative period.

Besides effectively reducing the internal fixation failure, the double-plate technology could also provide anatomical reduction and exhibited excellent bone healing with an average healing time for 3.6 months with minimal complications, such as plate breakage, slight restriction, and pain during overhead work. Stable fixation also provided favorable conditions for early functional exercise. The Constant Murley score of treated shoulder and contralateral shoulder was similar at the last follow-up. Rowe score and ASES score also indicate good recovery of the shoulder function.

The attentions of using double-plate technique for the treatment of the medial clavicle fractures should be noted: I. Avoid to cut and separate too much soft tissues in case of sternoclavicular joint dislocation and affecting the medial clavicle stability; II. For patients with osteoporosis, the operative action should be gentle and attention should be payed to avoid further crushing of the fracture; III. Anatomical reduction should be achieved, especially for the fracture in the sternoclavicular joint, to prevent the loss of clavicle length and the rotational deformity; IV. The plate combinations should be selected according to the distance between the fracture and the sternoclavicular joint as well as the fracture type: a straight or twohole row plate could be used for upper fracture fixation, and a three-hole L-shaped plate or a T-shaped plate could be used for front fracture fixation. $V$. The plates should be pre-shaped according to the shape of the clavicle to make sure better attachment to the clavicle. VI. At least 3 screws, usually $4-6$ screws, should be used for fixing the medial clavicle fracture with rafting technique.

\section{Limitations}

This is a relatively new technique with small number of cases involved. Meanwhile, there is the theoretically possibility of damaging the nerves and blood vessels behind the clavicle. Hence, our 
research needs to be confirmed by a larger randomized controlled study including preoperative assessment and conservatively treated control group.

\section{Conclusion}

In short, the double-plate vertical fixation technique was investigated to evaluate the therapeutic effect of extremely medial clavicle fracture. The anatomical reduction could be achieved under direct vision with stable fixation, which avoided the interference with the sternoclavicular and acromioclavicular joint activity. The outcome of follow up showed good bone healing rate and shoulder joint functional recovery indicating satisfactory early curative effect.

\section{Abbreviations}

ASES: American Shoulder and Elbow Surgeons

\section{Declarations}

\section{Acknowledgements}

We would like to thank Prof. Jincheng Wang who provided encouragement to write this paper and gave valuable advice.

\section{Authors' contributions}

HL and BY wrote the manuscript. ZZ anticipated the patients' follow-up. GR and JY analysed the data. CP revised and edited the manuscript. DW participated in the design of the study. All authors have read and approved the manuscript.

\section{Fundings}

This study was supported by the National Natural Science Foundation of China (Grant Nos. 81171681, 81701811, 81671804, and 81772456), Scientific Development Program of Jilin Province (Grant Nos. 20190304123YY, 20180623050TC and 20180201041SF), Program of Jilin Provincial Health Department (Grant No. 2019SRCJ001), Cultivation Program from the Second Hospital of Jilin University for National Natural Science Foundation (Grant No. KYPY2018-01), Youth Talents Promotion Project of Jilin Province (Grant No. 192004). Observers and authors were funded in the design of the study, collection and analysis of data, the writing of manuscript, and polishing of English manuscripts with mother tongue.

\section{Availability of data and material}


Data from the Department of Orthopedics, the Second Hospital of Jilin University. The datasets used and/or analyzed during the current study are available from the corresponding author on reasonable request.

\section{Ethics approval and consent to participate}

This study was conducted in accordance with the principles outlined in the Declaration of Helsinki and was approved by the Ethics Committee of the Second Hospital of Jilin University. Written informed consent to participate was obtained from all patients involved in the study. Patient data were kept anonymous to ensure confidentiality and privacy.

\section{Consent for Publication}

Not applicable.

\section{Competing interests}

The authors declared that they have no conflicts of interest to this work.

\section{References}

1. Nowak J, Mallmin H, Larsson S. The aetiology and epidemiology of clavicular fractures. A prospective study during a two-year period in Uppsala, Sweden. Injury 2000; 31: 353-8.

2. Kendal JK, Thomas K, Lo IKY, Bois AJ. Clinical outcomes and complications following surgical management of traumatic posterior sternoclavicular joint dislocations: a systematic review. JBJS Rev 2018; 6(11): e2.

3. Reghine ÉL, Cirino CCl, Neto AA, Varallo FR, Évora PRB, de Nadai TR. Clavicle Kirschner wire migration into left lung: a case report. Am J Case Rep 2018, 19: 325-8.

4. Lee YS, Lau MJ, Tseng YC, Chen WC, Kao HY, Wei JD. Comparison of the efficacy of hook plate versus tension band wire in the treatment of unstable fractures of the distal clavicle. Int Orthop 2009, 33(5): 1401-5.

5. Kim KC, Shin HD, Cha SM. Surgical treatment of displaced medial clavicle fractures using a small Tshaped plate and tension band sutures. Arch Orthop Trauma Surg 2011, 131(12): 1673-6.

6. Gille J, Schulz A, Wallstabe S, Unger A, Voigt C, Faschingbauer M. Hook plate for medial clavicle fracture. Indian J Orthop 2010, 44(2): 221-3.

7. Der Tavitian J, Davison JN, Dias JJ. Clavicular fracture non-union surgical outcome and complications. Injury 2002, 33(2): 135-43. 
8. Rikli DA, Businger A, Babst R. Dorsal Double-Plate Fixation of the Distal Radius. Eur J Trauma Emerg Surg 2007, 33(1): 99-109.

9. Bessho Y, Okazaki M, Nakamura T. Double plate fixation for correction of the malunited distal ulna fracture: a case report. Hand Surg 2011, 16(3): 335-7.

10. Kaipel M, Majewski M, Regazzoni P. Double-plate fixation in lateral clavicle fractures-a new strategy. J Trauma 2010, 69(4): 896-900.

11. Suter C, Majewski M, Nowakowski AM. Comparison of 2 plating techniques for lateral clavicle fractures, using a new standardized biomechanical testing setup. J Appl Biomater Funct Mater 2018, 16(2): 107-12.

12. Constant CR, Murley AH. A clinical method of functional assessment of the shoulder. Clin Orthop Relat Res 1987, 214: 160-4.

13. Rowe CR, Patel D, Southmayd WW. The Bankart procedure: a long-term end-result study. J Bone Joint Surg Am 1978, 60: 1-16.

14. Richards RR, An KN, Bigliani LU, Friedman RJ, Gartsman GM, Gristina AG, et al. A standardized method for the assessment of shoulder function. J Shoulder Elbow Surg 1994, 3(6): 347-52.

15. Throckmorton T, Kuhn JE. Fractures of the medial end of the clavicle. J Shoulder Elbow Surg. 2007, 16(1): 49-54.

16. Bartonícek J, Fric V, Pacovský V. Displaced fractures of the medial end of the clavicle: report of five cases. J Orthop Trauma 2010, 24(4): e31-5.

17. Partal G, Meyers KN, Sama N, Pagenkopf E, Lewis PB, Goldman A, et al. Superior versus anteroinferior plating of the clavicle revisited: a mechanical study. J Orthop Trauma 2010, 24(7): $420-5$.

\section{Tables}

Table 1. Edinburgh classification and follow-up observations of 9 patients treated with double-plate fixation for medial clavicle fractures 


\begin{tabular}{|c|c|c|c|c|c|c|c|}
\hline $\begin{array}{l}\text { Patient } \\
\text { Number }\end{array}$ & $\begin{array}{l}\text { Edinburgh } \\
\text { Classification }\end{array}$ & $\begin{array}{l}\text { Follow- } \\
\qquad \begin{array}{c}\text { Up } \\
\text { (mo) }\end{array}\end{array}$ & $\begin{array}{c}\text { Evidence of } \\
\text { Union on } \\
\text { Radiography } \\
\text { (mo) }\end{array}$ & $\begin{array}{l}\text { Range of } \\
\text { Motion }\end{array}$ & $\begin{array}{c}\text { Pain } \\
\text { During } \\
\text { Rest } \\
\text { (VAS } \\
0-10)\end{array}$ & $\begin{array}{c}\text { Pain } \\
\text { During } \\
\text { Overhead } \\
\text { Work }\end{array}$ & $\begin{array}{l}\text { Satisfaction } \\
\text { (VAS 0-10) }\end{array}$ \\
\hline 1 & B1 & 8 & 6 & Full & 0 & 0 & 10 \\
\hline 2 & B1 & 12 & 3 & Full & 0 & 0 & 10 \\
\hline 3 & $\mathrm{~A} 1$ & 6 & 6 & $\begin{array}{c}\text { Slight } \\
\text { restriction }\end{array}$ & 0 & 5 & 6 \\
\hline 4 & $\mathrm{~A} 2$ & 18 & 3 & Full & 0 & 0 & 10 \\
\hline 5 & A1 & 12 & 3 & Full & 0 & 0 & 10 \\
\hline 6 & B2 & 9 & 3 & Full & 0 & 0 & 10 \\
\hline 7 & B1 & 6 & 3 & Full & 0 & 0 & 10 \\
\hline 8 & B1 & 9 & 3 & Full & 0 & 2 & 8 \\
\hline 9 & $\mathrm{~A} 2$ & 12 & 3 & Full & 0 & 0 & 10 \\
\hline
\end{tabular}

Table 2. Functional assessments and clinical outcomes of 9 patients treated with double-plate fixation for medial clavicle fractures 


\begin{tabular}{|c|c|c|c|c|c|c|c|}
\hline $\begin{array}{l}\text { Patient } \\
\text { Number }\end{array}$ & $\begin{array}{l}\text { Constant Murley } \\
\text { score of Treated } \\
\text { Shoulder }\end{array}$ & $\begin{array}{c}\text { Constant Murley } \\
\text { score of } \\
\text { Contralateral } \\
\text { Shoulder }\end{array}$ & $\begin{array}{l}\text { Rowe } \\
\text { Score }\end{array}$ & $\begin{array}{l}\text { ASES } \\
\text { score }\end{array}$ & $\begin{array}{l}\text { Implant } \\
\text { Removed }\end{array}$ & $\begin{array}{l}\text { Return } \\
\text { to work }\end{array}$ & $\begin{array}{c}\text { Other } \\
\text { Complication }\end{array}$ \\
\hline 1 & 100 & 100 & 100 & 100 & No & Retired & None \\
\hline 2 & 98 & 100 & 100 & 100 & Yes & Yes & $\begin{array}{c}\text { Plate } \\
\text { breakage }\end{array}$ \\
\hline 3 & 78 & 94 & 92 & 93 & No & Retired & None \\
\hline 4 & 100 & 100 & 100 & 100 & Yes & Yes & None \\
\hline 5 & 98 & 100 & 100 & 100 & No & Yes & None \\
\hline 6 & 92 & 100 & 93 & 92 & No & Yes & None \\
\hline 7 & 94 & 96 & 95 & 93 & No & Yes & None \\
\hline 8 & 87 & 97 & 91 & 89 & No & Retired & None \\
\hline 9 & 100 & 100 & 100 & 100 & No & Yes & None \\
\hline
\end{tabular}

Figures 

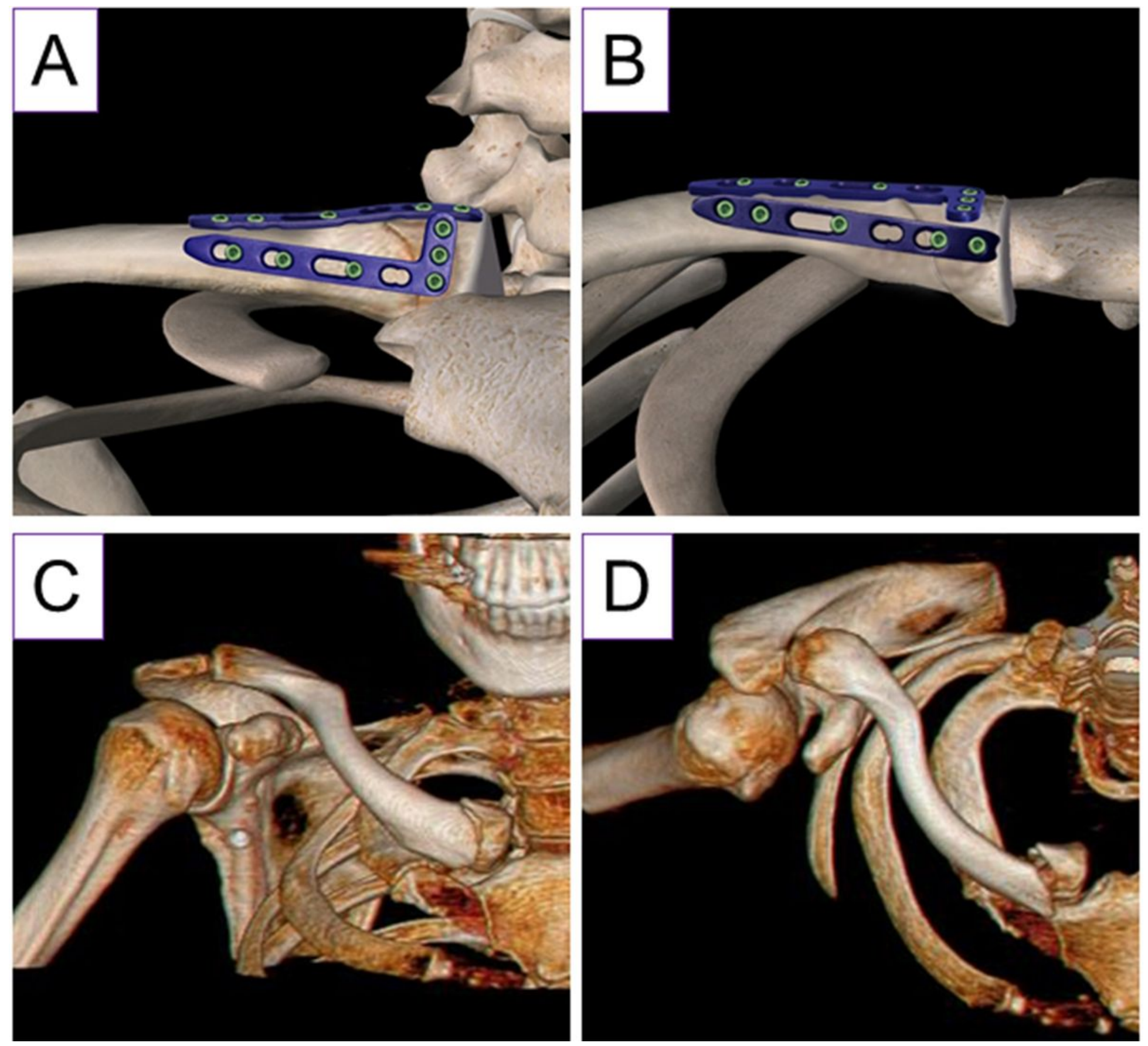

Figure 1

Front view $(A, C)$ and top view $(B, D)$ of the plate placement and the 3D reconstruction of a female patient complaint of medial clavicle fracture. 

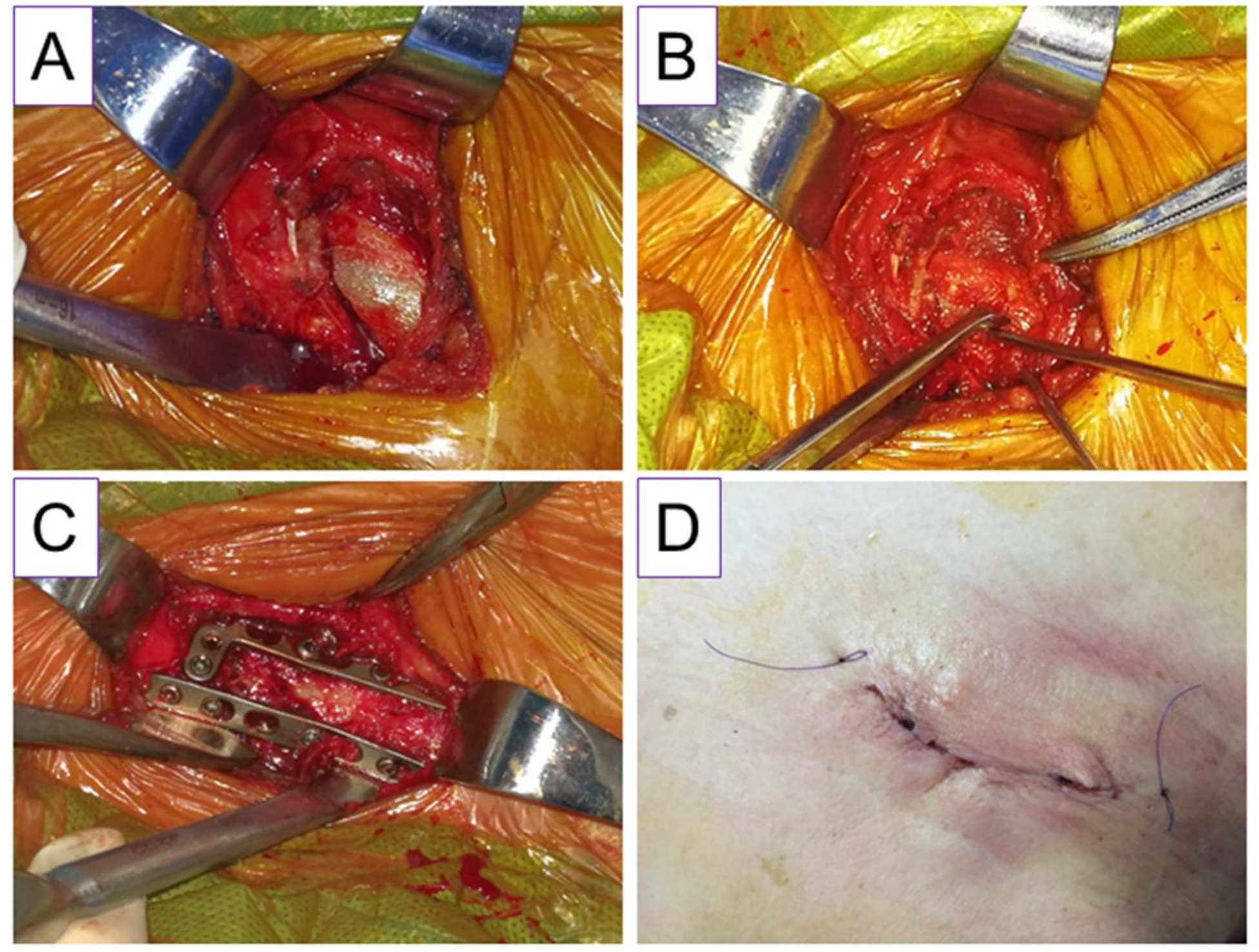

Figure 2

Operative views during double-plate fixation using two $2.4 / 2.7 \mathrm{~mm}$ locking compression plates: Surrounding soft tissue and inserted periosteum in the fracture end were removed (A); Kirschner-wire was used for temporary fixation (B); Two plates were vertically placed (C); General view of the wound (D). 


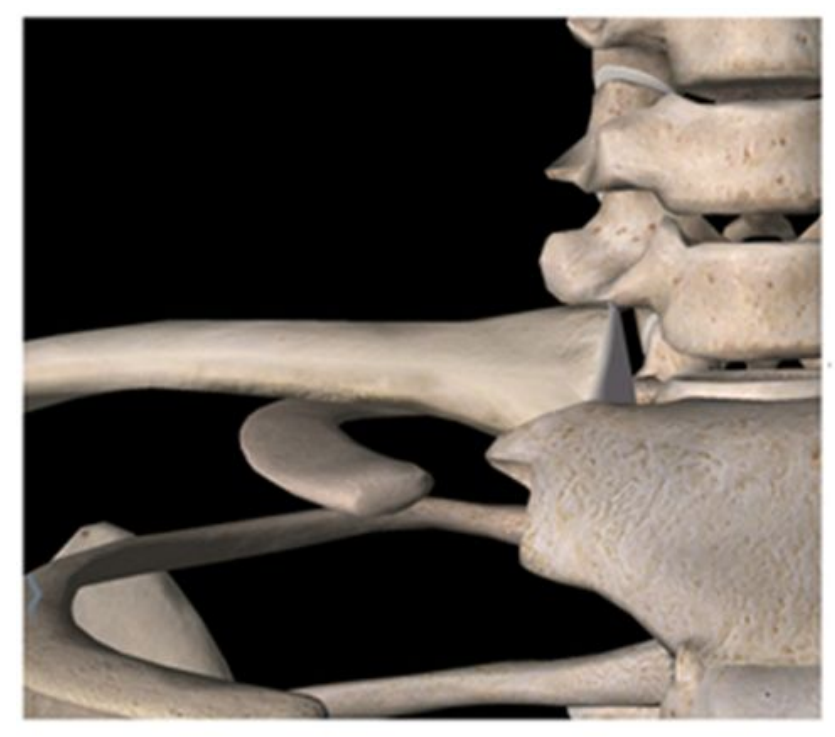

\section{Upper fixing plates}
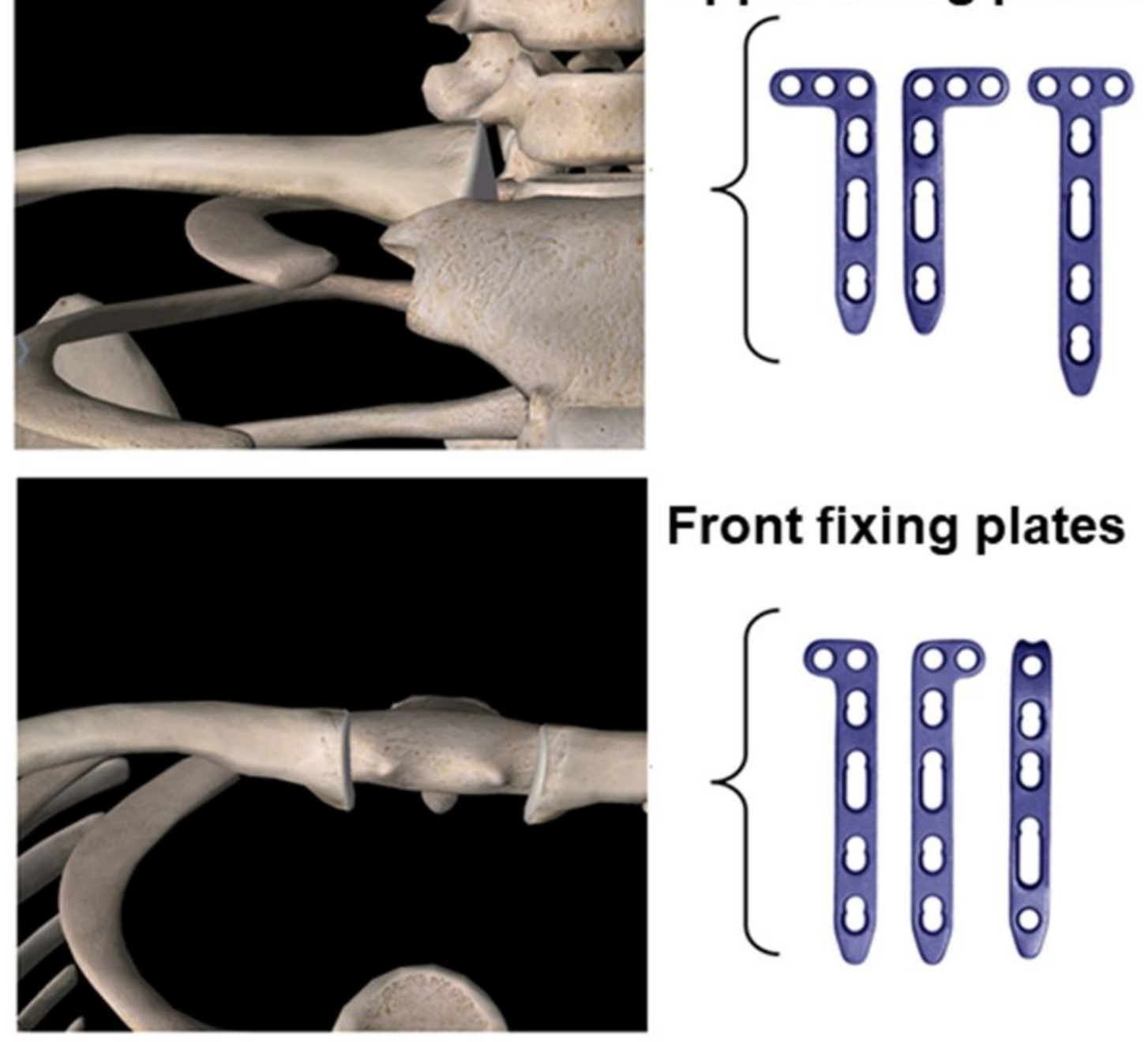

\section{Front fixing plates}

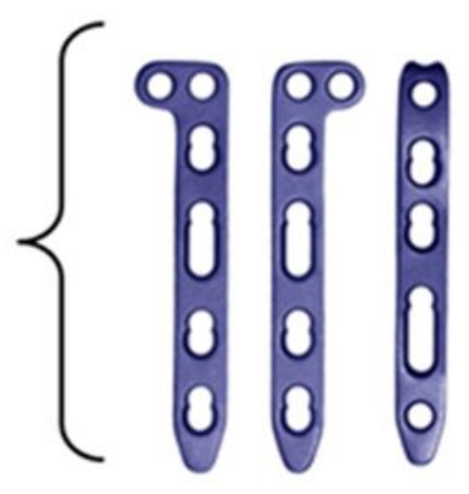

\section{Four kinds of plate combinations}

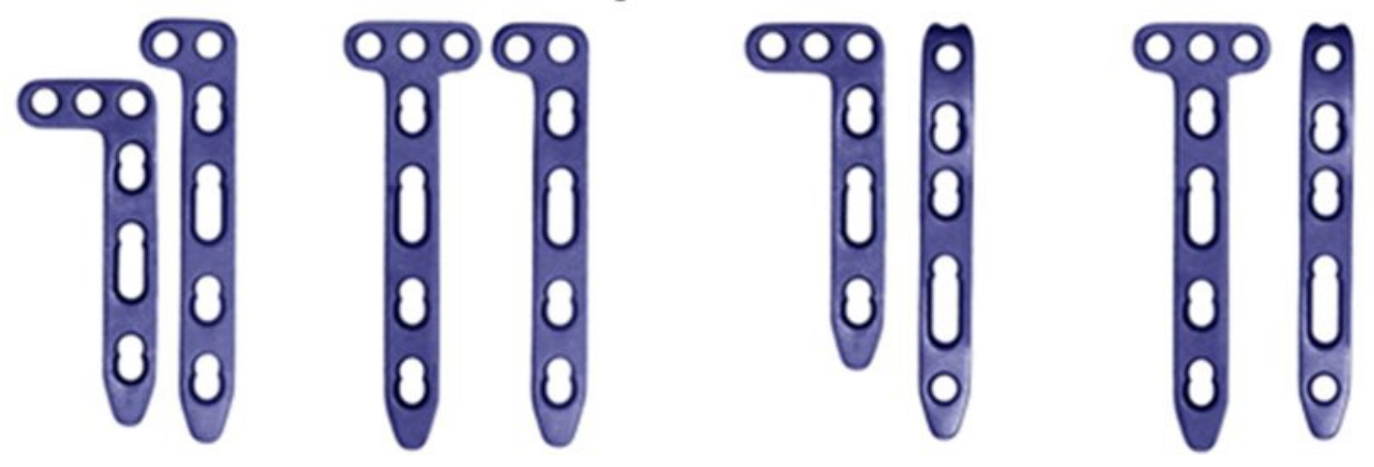

Figure 3

Four kinds of plate combination for medial clavicle fracture fixation using double-plate system. 

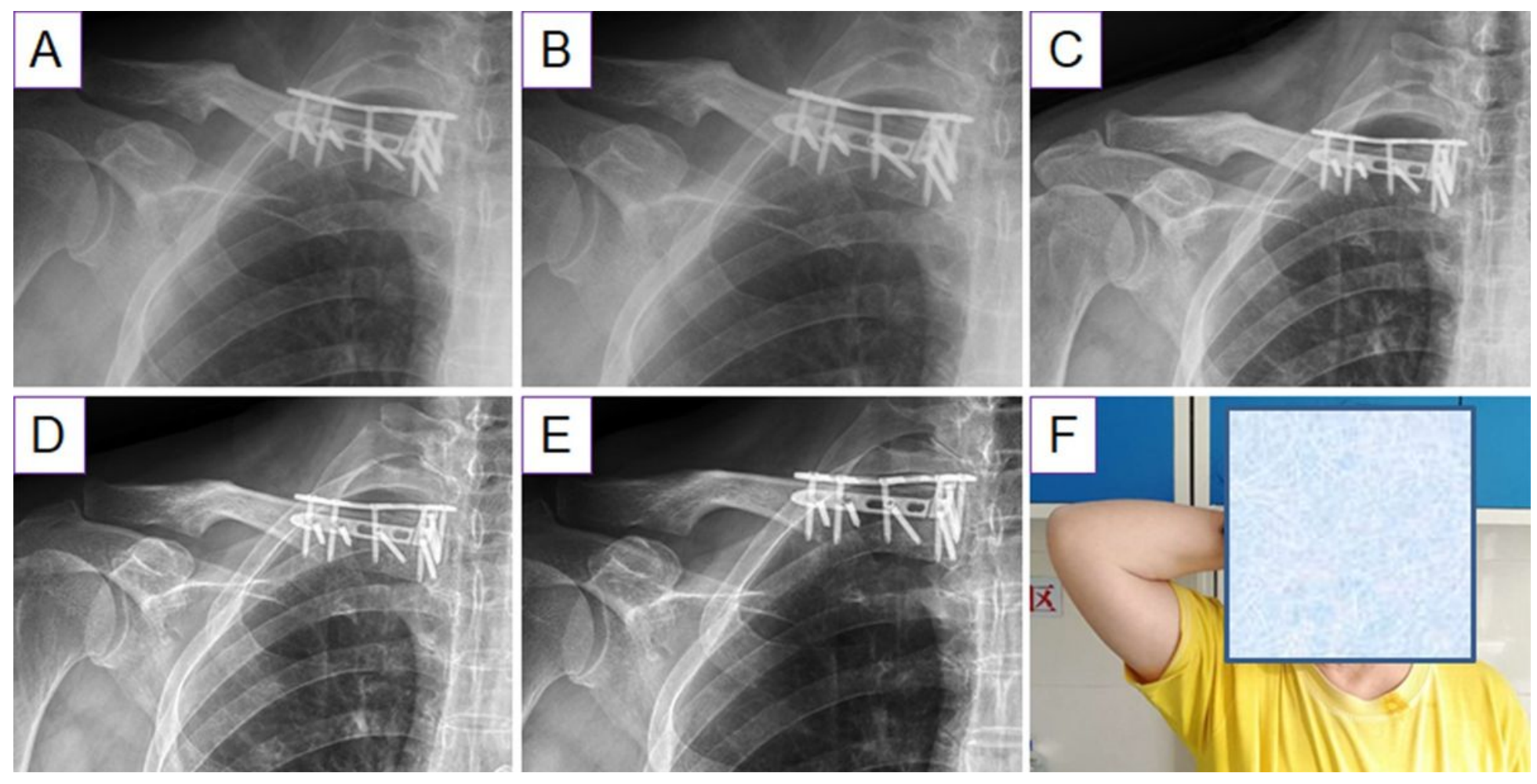

\section{Figure 4}

X-ray radiographs at 1 day (A), 3 months (B), 6 months (C), 9 months (D) and 12 (E) months of a female patient after double-plate fixation, as well as the shoulder joint extension (F) at 3 months post-operation. 